\title{
Consistency of Hemispheric Accuracy in Inferring Sentences and Dialogs
}

\author{
Arifuddin, I Made Sujana \\ Language and Arts Department, Faculty of Teachers Training and Education, \\ University of Mataram, Mataram, Indonesia \\ e-mail: arifpgn@yahoo.com; denasujana@gmail.com
}

\begin{abstract}
Broca's and Wernicke's discovery concerning brain language function remains debatable. The research questions: a) Is there a significant difference of accuracy among the rh, the lh, and the rh-lh in inferring auditory sentences? b) Which hemisphere shows the highest accuracy? and c) Do the rh, lh and rh-lh show consistent hemispheric accuracy when inferring sentences and short dialogs? The research results are useful for clarifying controversies against brain language function and as a foundation of "hemispheric-based listening". This study employed Behavioral Test with Post-test Only design. Sample involved 120 students. Data were collected through a test and analyzed with Two-way Anova. It is found that the hemispheric accuracy among the $\mathrm{rh}, \mathrm{lh}$ and $\mathrm{rh}-\mathrm{lh}$ in inferring auditory sentences is significantly different; the lh shows the highest accuracy in inferring auditory sentences; and the rh, lh and rh-lh show inconsistent hemispheric accuracy when inferring sentences and short dialogs.
\end{abstract}

Key words: hemisphere, bilateral, inferring, auditory, behavioral test

There has been a long debate about which brain hemisphere supports language processes. In the early 19th century, based on the examination of the aphasics' brains, Broca and Wernicke discovered that the left hemisphere (hereafter $\mathrm{lh}$ ) absolutely plays the language function known as Broca's and Wernicke's areas (Chudler, 2007). The classical brain lesionbehavior approaches suggest that the left hemisphere posterior lesions including Wernicke's area speak fluently and produce at least parts of a sentence with seemingly correct syntactic structures, but they reflect limitations to process content words (Friederici, Cramon, \& Kotz, 1999). This "discovery" has been widely accepted as a fundamental neurolinguistic theory until now. 
Meanwhile, many scientists express the weaknesses of the discovery. The weaknesses deal with, for example: a) it was merely based on the detected language area of aphasic, b) it was limited to subjects' capacity in producing and comprehending simple utterances, not dealt with the more specific and complex aspects of utterances; and c) in relation to the present study, the examination did not use auditory sentences as stimuli. In general, 'the opposing' scientists hypothesize that the language processing of the normal subjects might be controlled by different areas or hemispheres of the brain. Take for example Campbell and Reece (2002), who emphasize that language is processed by some areas of cerebral cortex and, in line with this hypothesis, Feldman (1996), who confirms that the two hemispheres cooperate to interpret linguistic input and they are likely to modify their roles. It means that the language function of the cerebral hemisphere is not dominated by the $\mathrm{lh}$ as discovered by Broca and Wernicke.

Such a controversy and also Arifuddin's (2005) research result show that the right hemisphere (hereafter rh) is more accurate in dealing with the students' hemispheric accuracy in inferring auditory sentences. And this is the second preliminary study for the next study with broader scope entitled "The Consistency of Hemispheric Accuracy in Inferring Auditory Utterances with Different Complexity".

There are three research questions to be solved: a) Is there a significant difference of hemispheric accuracy among the rh, the $\mathrm{lh}$, and the right-left (or bilateral) (hereafter rlh) hemispheres in inferring auditory sentences? b) Among the rh, the lh, and the rlh, which one shows the highest hemispheric accuracy in inferring auditory sentences? c) Do the rh, th and rh-lh show consistent hemispheric accuracy when inferring sentences and short dialogs?

The present study aims at comparing hemispheric accuracy among the $\mathrm{rh}$, the $\mathrm{lh}$, and the rlh in inferring auditory sentences and ascertaining which hemisphere shows the highest accuracy in inferring auditory sentences and the consistency of hemispheric accuracy in inferring utterances with different complexity.

The contributions of the present study are to: 1) be a further clarification of controversy against the language function of brain hemispheres; 2) provide empirical information about the hemispheric accuracy of the rh, $\mathrm{h}$, and the rlh in inferring auditory sentences; 3) be a foundation of further study on the effectiveness of "hemispheric-based listening practices" in language learning; and 4) encourage linguists to do neurolinguistic studies. 


\section{METHODS}

The present study employs the Behavioral Test (Fromkin \& Rodman, 1989). The population involved 200 students of the English language education program of the Faculty of Teacher Training and Education, the State University of Mataram and another 120 students representing the sample were drawn from the same program through Equal Allocation Stratified Random Sampling (Wiersma, 1991). The data were scores of hemispheric accuracy (lh, rh, rlh) in inferring utterances collected through two kinds of test, sentence inference test and dialog inference test consisting of 45 items respectively. And the data were analyzed with "Two-way Anova" and their Critical Difference was tested with "Tukey HSD Procedure."

\section{FINDINGS AND DISCUSSION}

There are three groups of scores collected through three tests, consistent with the number of "type" of hemisphere -- the rh, the lh, and the rlh. The following are the totals and mean score of accuracy in inferring auditory sentences for each hemisphere and the summary of Anova table.

Table 1. The Summary of Data of Hemispheric Accuracy

\begin{tabular}{lll}
\hline \multicolumn{1}{c}{ RH } & \multicolumn{1}{c}{ LH } & \multicolumn{1}{c}{ RLH } \\
(Through Left Ear) & (Through Right Ear) & (Through Left-Right Ears) \\
\hline$\sum=\mathbf{7 4 8}$ & $\sum=\mathbf{1 0 2 7}$ & $\sum=\mathbf{8 0 4}$ \\
$\boldsymbol{\mu}=6.2333$ & $\boldsymbol{\mu}=8.5583$ & $\boldsymbol{\mu}=6.7000$ \\
\hline
\end{tabular}

The homogeneity and normality of the three groups of data were tested with SPSS 11.10 program.

Based on the result of Kolmogorov-Smimov test (Lilifors Significance Correction), the significance levels of the $\mathrm{rh}$, the $\mathrm{lh}$, and the rlh are .176, .263 , and .160 respectively. In the present study, the standard of significance level $\alpha=.05$ is used and the obtained significance level is referred to as $p$. Those values are higher than the standard value of significance $\alpha=.05$. Statistically, $p>\alpha$. Therefore, the three groups of scores are normally distributed.

Just as the calculation of normality, the hemogeneity of each group of scores was also calculated. Since the scores of hemispheric accuracy were 
obtained from three measurements of the rh, the $\mathrm{lh}$, and the rlh which were theoretically predicted to have different levels of accuracy, the test of homogeneity was separately done for each group of scores, not mixed. Based on statistical analysis with SPSS 11.10 program, Based on Mean of Levene Statistic, it indicates that the homogeneity of data of hemispheric accuracy of the rh, the $\mathrm{lh}$ and the rlh are $.106, .208$, and .181 respectively. In the present study, the standard of significance level $\alpha=.05$ is used and the obtained significance level is referred to as $p$, and all values of $p>\alpha$. Thus, each group of scores is homogeneous. As a result, some conditions of parametric statistical analysis are satisfied.

The next step is analyzing data. The three groups of scores were analyzed statistically using SPSS 11.10 program, and the results of the analysis are presented in the Anova summary in Table 2.

\section{Table 2. Anova Summary}

\begin{tabular}{lccccc}
\hline $\begin{array}{l}\text { Sum of } \\
\text { Squares }\end{array}$ & & Df & Mean Square & F & Sig. \\
$\begin{array}{l}\text { Between } \\
\text { Groups }\end{array}$ & 363,072 & 2 & 181,536 & 29,295 &, 000 \\
$\begin{array}{l}\text { Within } \\
\text { Groups }\end{array}$ & 2212,258 & 357 & 6,197 & & \\
Total & 2575,331 & 359 & & & \\
$\begin{array}{l}\mathrm{df}=(\mathrm{g}-1) /(\mathrm{N}-\mathrm{g})=(3-1) /(360-3) \\
\quad=2 / 357 .\end{array}$
\end{tabular}

The $\mathrm{df}$ is used as the basis for further consultation with the table of critical value of $F$. Since the critical value of $F$ at significance level .05 with df $2 / 357$ is 2.99 and $F$ obtained 29.295, there is a significant difference among the three groups of scores. And based on the computation of significance difference test of each pair of totals, Critical Difference (CD) is 90.28 .

The Critical Difference (CD) value is then used as a standard for determining the significant difference of each pair of totals. The total of each group of scores is presented here, Total of rh $(\mathrm{T} 1)=748$, Total of $1 \mathrm{~h}$ $(\mathrm{T} 2)=1027$, and Total of rlh (T3) $=804$. Having tested with the CD value, it is found that the difference of: 
$\mathrm{T} 1-\mathrm{T} 2=279:$ Significant

$\mathrm{T} 1-\mathrm{T} 3=56 \quad:$ Not significant

$\mathrm{T} 2-\mathrm{T} 3=223:$ Significant

As shown above, the total score of the hemisphere is far higher than that of the rh and the same case also occurs between the rlh and the rh. As a result, the difference between the two groups of scores is significant. This is also supported by the critical value of F 29.295. Thus, as a whole, the rh, the $\mathrm{lh}$ and the rlh show significant difference of accuracy in inferring auditory sentences, although a question arises, "Why is the difference between the rh and the rlh not significant?"

Above all, it is worthy presenting the relationship between the research finding and previous theories or studies in the same area. The finding is relevant to Harpaz's (2006) study showing that there is a strong tendency for the two hemispheres to distribute knowledge and skills, including the tendency for the left hemisphere to process language. Padji (2003) also reports that language production is the lh specific task. Explicitly, only one hemisphere plays language functions.

In relation to the discussion of tasks of cerebral cortex, there are two groups of scientists, the localizationists and the antilocalizationists. The former believe that different hemispheres, even different areas of the brain, play different functions, agree that each hemisphere or region of brain plays different roles, while the latter believe that there is no strict labor division of each area of the brain. In accordance with verbal language, the localizationists' view that the processing, including producing of language, is dominantly controlled by the $\mathrm{lh}$. Thus, there is a different language capacity of the two hemispheres. And more extremely, only the lh is responsible for language functions.

However, the research finding is contrary to Gazzaniga's (2003) view indicating that the two hemispheres participate simultaneously in all activities that we do. Gazzaniga's view also implies that the rh may also play the same role as usually acted by the $\mathrm{lh}$, depending on the types and complexity of the stimulus being received. This view, however, also remains debatable.

In addition, based on Tukey HSD test, it is found that the difference between total 1 and total 2 (T1 - T2) is significant. It means that the rh and the $\mathrm{lh}$ show significant difference of hemispheric accuracy. The left hemisphere is more accurate than the rh. Such a finding is consistent with 
Broca's and Wernicke's "discovery" showing that the lh controls and processes language, although according to Gazzaniga (2003), the discovery of the two neurolinguistic pioneers was merely based on the ability of the aphasics, those who lost speaking ability to select words and construct sentences.

Certainly, there are also other scientists who agree with the great discovery, for example, Kimura with his Dichotic Listening Method, although with different emphasis (Paivio \& Begg, 1981). Based on his experiment, Kimura found that nonverbal stimulus, such as melody, is more accurately recognized with the rh. It is possible that Kimura's finding about hemispheric capacity is different from that of different studies using more complex verbal stimuli.

Views supporting the idea that language is dominantly controlled by the lh are also stated by other scientists, namely Armstrong (1987), Vaid and Hall (1991), Boysson-Bardies (1999), Dryden and Vos (2001), Djajasudarma (2004), Steinberg, Nagata, and Aline (2001), Dardjowidjojo (2003), Gazzaniga (2003), and Hotz (2007). As stated before, these findings and views emphasize that there is a tendency for a certain hemisphere to dominate language role.

However, the finding is contrary to some other findings, for example, the one reported by Gazzaniga (2003) which does not agree with the view stating that there is an extreme job description between the left hemisphere and the rh. Gazzaniga is convinced that the two "specialized" hemispheres are involved in all activities which human beings do. This view indicates that the rh can also play the roles commonly performed by the lh.

Similarly, Gunese and Selinger (in Brown, 1987) also express that language processing requires the involvement of the rh. They conclude that there is a great involvement of the rh in language processing of bilinguals who acquire the second language in late adulthood, long after they acquired their first language, and bilinguals who acquire the second language in nonformal context. More specifically, Taylor (1990), also supported by Hernowo (2002), believes that in identifying words, the rh is equipped with the capacity to process semantic aspect and holistic stimuli more quickly, while the $\mathrm{lh}$ is able to process phonetic stimulus and order of events more accurately. This statement supports the views that the two hemispheres can perform language functions.

Based on those views, there is role interdependency between the rh and the lh. Feldman (1996) also reports that in normal, nonsplit brain 
person, the two hemispheres cooperate, dependent on each other, resulting in maximum performance. Knecht, et al. (2002) emphasize that language is considered a function of either the left, or in exceptional cases, the right side of the brain. In other words, the two hemispheres work together to interpret and react to the stimulus or input. As an example, when someone produces or processes language input, the two hemispheres simultaneously control the task.

In line with it, Steinberg, Nagata, and Aline (2001) state that the rh uses semantic gaps related to words which facilitate ones to make inference, comprehend metaphors, and organize global structure of discourse. This is the primary basic theory of the present study. The view is expressed by Kent and Miolo in Dardjowidjojo (2000) that the rh also functions in producing utterances or language vocalization. It is also relevant to the result of Arifuddin's (2005) preliminary study on the hemispheric accuracy of English language students in identifying the topics of auditory associated English words groups. This inconsistency requires further studies involving various language aspects.

Furthermore, based on the significance test for the difference among the totals, it is found that $\mathrm{T} 1-\mathrm{T} 3$ is not significant. It implies that there is no significant difference between the right hemisphere and the right-left (or bilateral) hemispheres in inferring sentences. This finding is supported by Campbell and Reece's (2002) reports, based on some modern, detailed studies, showing that language is processed by some areas in cerebral cortex. It implies that even the different parts or areas may cooperate like an integrated system and change their roles any time. The statement indicates that there is a possibility for two different areas or hemispheres to exchange their roles. Implicitly, these antilocalizationists question the truth of the previous inventions showing that only the $\mathrm{lh}$ is able to play language role.

However, the finding just mentioned is not consistent with Rose and Nicholl's (2002) view that "two is better than one" which strengthens the acceptability of the view indicating that some areas or two hemispheres share their tasks, including language processing. Concretely, when someone is capable of performing language function properly, there is a great possibility for the "mute" hemisphere to also participate in language role.

Further discussion focuses on the significant difference between T2$\mathrm{T} 3$, $\mathrm{h}$ and rlh. As shown before, the difference between T2-T3 is 
significant. It indicates that the $\mathrm{lh}$ and the rlh show significant difference of accuracy in inferring sentences. Statistically, the lh shows higher level of accuracy than the rlh in inferring auditory sentences.

In contrast, this finding is not consistent with Szaflarski's (2004) finding that 25-year old adults tend to use the two hemispheres simultaneously in language processing and using. Like Szaflarski, Gunese and Selinger (in Brown, 1987) it is also found that there is a great involvement of the rh in language process of late bilinguals as stated before. In accordance with this, there is role interdependency between the $\mathrm{rh}$ and the lh. As stated before, Feldman (1996) found that in a normal, nonsplit brain person, the two hemispheres cooperate, they work together to interpret and react to the stimulus. Even, according to Meir (2002), the different parts or areas of cerebral cortex share their tasks and are likely to exchange their roles any time. It indicates that it is possible for the different areas or hemispheres to exchange their roles, not tightly dominated by a certain area or hemisphere of brain.

Those findings indicate that the two hemispheres are likely to cooperate in interpreting and reacting to the stimulus. Generally, a child suffering from language loss due to the $\mathrm{lh}$ injury is able to recover his or her speaking ability because the task for producing and processing language which was previously done by the lh is now served by the rh. The two hemispheres share the language functions of cerebral cortex. In addition, the rh also takes part in performing other language cases or aspects.

Furthermore, the total scores, mean and ranks of hemispheric accuracy in inferring dialogs are presented in Anova preparing table. The data are used to answer the following research questions: 2) Is rh more accurate than rh and rh-lh in making inference from a short dialog? and 3) Is the accuracy of $\mathrm{rh}, \mathrm{h}$, and rh-lh in making inference from short dialogs consistent with that of sentences?

The $\mathrm{F}$ value indicating significant difference obtained through Oneway Anova is 12.916, far higher than $\alpha=.05$. It indicates that the hemispheric accuracy of the three "groups" of hemisphere in inferring dialogs is significantly different.

Based on pairwise comparisons of mean difference, the difference of hemispheric accuracy in inferring sentences and dialogs is 1.867, higher than 95\% Confidence Interval for Difference 1.521 dan $\alpha=.05$. The significant difference of the two means is also indicated by the result of $\mathrm{F}$ test 112.214 which is far higher than that of $\mathrm{F}$ table 2.99. 
Table 3. Anova Preparing Table

\begin{tabular}{lllll} 
Sttearances & \multicolumn{1}{c}{ RH } & \multicolumn{1}{c}{ LH } & \multicolumn{1}{c}{ RLH } & $\begin{array}{r}\text { Total } \\
\text { Mean }\end{array}$ \\
\hline Sentence & $\begin{array}{l}\sum=748 \\
\mu=6,233\end{array}$ & $\begin{array}{l}\sum=1027 \\
\mu=8,558\end{array}$ & $\begin{array}{l}\sum=804 \\
\mu=6,700\end{array}$ & 7,1639 \\
& Rank: III & Rank: I & Rank: II & \\
Dialog & $\sum=697$ & $\sum=535$ & $\sum=675$ & \\
& $\mu=5,808$ & $\mu=4,458$ & $\mu=5,625$ & 5,2972 \\
& Rank: I & Rank: III & Rank: II & \\
\hline
\end{tabular}

Supporting evidence is provided by the result of Tests betweenSubjects Effects showing that probability coefficient of interaction HEMI*UTT .001 is lower than .005. It indicates that there is an interaction between types of utterance and hemispheric accuracy. In addition, the results of LSD and Duncan tests show that either types of utterance or groups of hemispheres independently affect hemispheric accuracy because its probability (p) value $.00<\alpha=.05$. This suggests that there is a significant mean difference of hemispheric accuracy in inferring sentences and dialogs.

Above all, there is an "inconsistency" of hemispheric accuracy in inferring utterances with different complexity. In other words, the level of hemispheric accuracy in language processing depends on types and complexity of stimuli and utterances. This finding is relevant to Gazzaniga's (in Greenfield, 2003) view suggesting that there is no job division of the rh and the $\mathrm{lh}$, the two specialized hemispheres take part in all acitivities that a person does. It suggests that the rh could do what the $1 \mathrm{~h}$ usually does.

\section{CONCLUSION AND SUGGESTION}

The results show that: 1) Hemispheric accuracy among the rh, the lh, and the right-left (or bilateral) (hereafter rlh) hemispheres in inferring auditory sentences is significantly different and the lh shows the highest hemispheric accuracy in such a task, 2) In inferring short dialogs, the rh is more accurate than the $\mathrm{lh}$ and the rlh, 3) The rh, $\mathrm{lh}$ and rh-lh show inconsistent hemispheric accuracy when inferring sentences and short 
dialogs. Thus, it is hypothesized that there is an inconsistency of hemispheric accuracy in inferring utterances with a variety of complexity.

Accordingly, use the brain hemisphere with the highest accuracy of inference to improve auditory (or listening) skills in language learning. For example, while listening to a recorded dialog, students need to activate their rhs!

\section{ACKNOWLEDGEMENT}

Thanks to DP2M Dikti (Department of National Education Republic of Indonesia) as a sponsor and other institutions or individuals who have actively participated in the present study.

\section{REFERENCES}

Armstrong, T. (1987). In their own way: Discovering and encouraging your child's personal learning style. Long Angeles: Jeremy P.Tarcher.

Arifuddin. (2005). The hemispheric accuracy of English education students of University of Mataram in identifying the topics of associated English words groups. Unpublished master thesis, State Teacher Training Institute of Singaraja, Bali.

Boysson-Bardies, B. (1999). How language comes to children. London: A Bradford Book.

Brown, H. D. (1987). Principles of language learning and teaching. New Jersey: Prentice-Hall.

Campbell, N., \& Reece, J. B. (2002). Biology (6th ed.). San Francisco: Pearson Education.

Chudler, E. (2007). Brain and communication. Retrieved March 5, 2007, from http://ibrary.thinkquest.org/26451/contents/spokenword/thebrainandcomm unication.htm

Dardjowidjojo, S. (2003). Psikolinguistik: Pengantar pemahaman bahasa manusia. (Psycholinguistics: An Introduction to the understanding of human language). Jakarta: Yayasan Obor Indonesia.

Djajasudarma, F. (2004). Kerusakan bahasa dan otak manusia. (The impairment of language and human brain). Retrieved August 4, 2005, from http:/www.lemlit.unpad.ac.id/i.

Dryden, G., \& Vos, J. (2001). Revolusi cara belajar. (The learning style revolution). (Ward \& Translation Service, Trans.). California: Jalmar Press. 
Feldman, R. S. (1996). Understanding psychology. USA: McGraw-Hill.

Friederici, A. D., Cramon, D. Y., \& Kotz, S. A. (1999). Language related brain potentials in patients with cortical and subcortical left hemisphere lesions. Brain, 122(6), 1033-1047.

Fromkin, V., \& Rodman, R. (1989). An introduction to language. Sydney: Hold, Rinehart, and Winston.

Gazzaniga, M. S. (Director). (2003). Brain story [Motion picture 4]. Jakarta: P. T. Intermedia Prima Vision.

Greenfield, S. (2003). Brain story. London: BBC Worldwide.

Harpaz, Y. (2006). Hemispheric interdependence. Retrieved July 24, 2007, from http://www.human brain.org

Hernowo, (2002). Mengikat makna: Mengubah paradigma membaca dan menulis secara radikal. (Binding meaning: Changing reading and writing paradigm radically). Bandung: Kaifa.

Hotz, R. L. (2007). Brain language function. Retrieved March, 24, 2007, from http://www.talkingpage.org/artic008.html

Knecht, S., Floel, A., Drager, B., Breitenstein, C., Sommer, J., Henningsen, H., \& et al. (2002). Degree of language lateralization determines susceptibility to unilateral brain lesions. Nature Neuroscience, 5, 695-699.

Padji. (2003). Boosting children's brain skills. Bandung: Pionir Jaya.

Rose, C., \& Nicholl, M. J. (2002). Cara belajar cepat abad XXI. (Accelerated learning for the $21^{\text {st }}$ century). (D. Ahimsa, Trans.). London: Judy Piatkus.

Steinberg, D. D., Nagata, H., \& Aline, D. P. (2001). Psycholinguistics. Malaysia: Pearson Education.

Szaflarski, J. P. (2004). Language center of brain shifts with age. Retrieved March, 24, 2007, from http://www.sciencedaily.com/releases/2004/04/ 040428062634. html.

Taylor, I. (1990). Psycholinguistics: Learning and using language. New Jersey: Prentice-Hall International.

Vaid, J., \& Hall, D. G. (1991). Neuropsychological perspectives on bilingualism: Right, left, and center. In Reynolds (Ed.), Bilingualism, multiculturalism and second language learning (pp. 81-112). New Jersey: Lawrence Erlbaum Associates.

Wiersma, W. (1991). Research methods in education (5th ed.). USA: Allyn and Bacon. 